\title{
Fatigue Performance of Recycled Hot Mix Asphalt: A Laboratory Study
}

\author{
Marco Pasetto ${ }^{1}$ and Nicola Baldo ${ }^{2}$ \\ ${ }^{1}$ Department of Civil, Environmental and Architectural Engineering, University of Padua, Via Marzolo 9, 35131 Padua, Italy \\ ${ }^{2}$ Polytechnic Department of Engineering and Architecture, University of Udine, Via del Cotonificio 114, 33100 Udine, Italy \\ Correspondence should be addressed to Nicola Baldo; nicola.baldo@uniud.it
}

Received 8 September 2016; Revised 2 February 2017; Accepted 7 February 2017; Published 26 February 2017

Academic Editor: Katsuyuki Kida

Copyright (c) 2017 Marco Pasetto and Nicola Baldo. This is an open access article distributed under the Creative Commons Attribution License, which permits unrestricted use, distribution, and reproduction in any medium, provided the original work is properly cited.

\begin{abstract}
The paper introduces and analyses the results of an experimental trial on the fatigue resistance of recycled hot mix asphalt for road pavements. Based on the gyratory compaction and the indirect tensile strength test, the mix design procedure has optimized nine different mixes, considering both conventional limestone and Reclaimed Asphalt Pavement (RAP), the latter used at different quantities, up to $40 \%$ by weight of the aggregate. A standard bitumen and two polymer modified binders were used for the production of the mixes. The fatigue study was carried out with four-point bending tests, each one performed at $20^{\circ} \mathrm{C}$ and $10 \mathrm{~Hz}$. The empirical stiffness reduction method, along with the energy ratio approach, based on the dissipated energy concept, was adopted to elaborate the experimental data. Unaged and aged specimens were checked, to analyse the ageing effects on the fatigue performance. In comparison with the control mixes, produced only with limestone, improved fatigue performance was noticed for the mixtures prepared with RAP, especially when made with polymer modified binders, under both aged and unaged conditions. Both the approaches adopted for the experimental data analysis have outlined the same ranking of the mixes.
\end{abstract}

\section{Introduction}

As a consequence of the continuous increase of the traffic loads recorded in the last decades, significant efforts have been made by the scientific community and the highway engineers to develop high performance hot mix asphalt. For example, asphalt rubber mixtures [1-4] and polymer modified asphalt concrete [5-11] are just few of the several technologies proposed and widely investigated over the years.

However, the scientific research has been focused also on different themes, for instance, the recycling of waste materials for the construction of road pavements, in order to save natural aggregates, which nowadays are less available [12$22]$. Hence, the study of high performance hot mix asphalt, characterized by aggregate structures made with recycled materials, gives the possibility of meeting the demand of high mechanical resistance as well as that of sustainability of the road construction.

Among the different waste materials investigated for recycling in the road pavements, the Reclaimed Asphalt
Pavement (RAP) aggregates are widely considered a fundamental resource to implement the sustainability philosophy in the road construction [23-27]. Several researchers have demonstrated the beneficial effects given by the use of RAP aggregates in the lithic skeleton of the hot mix asphalt, for example, a higher resistance to permanent deformation in comparison with traditional bituminous mixtures [23-25, 28, 29]. However, the effect of the RAP material on the fatigue performance of the mix has to be still completely understood; in fact, some researchers have found a reduction of the fatigue life $[25,29]$, basically associated with a brittle behaviour of the asphalt concrete, due to the high stiffness of the aged binder of the RAP grains [28]. Contrary findings were observed in other investigations [14, 23], primarily in case of use of a rejuvenator agent, to improve the response of the aged RAP bitumen $[24,26]$. Recent studies have even verified a comparable fatigue life between RAP asphalt concrete and high modulus hot mix asphalt $[29,30]$. Currently such topic deserves to be still investigated, in order to achieve a deep understanding of the fatigue performance of RAP asphalt concrete. 


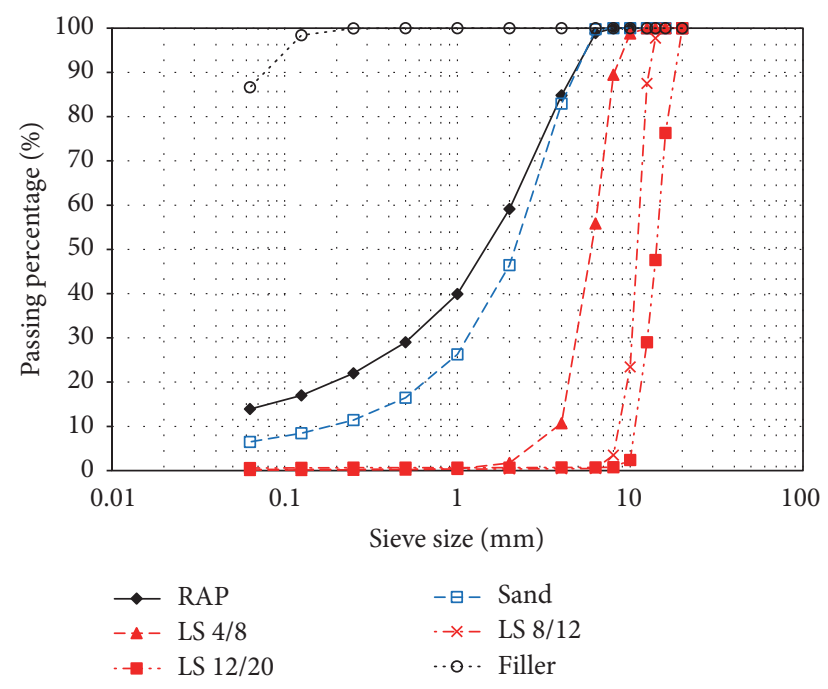

FIGURE 1: Grading curves of the aggregates.

In the present laboratory research, the fatigue performance of polymer modified hot mix asphalt, for base courses of flexible pavements, made with Reclaimed Asphalt Pavement (RAP) aggregates, has been studied by means of the four-point bending test (4PBT), using the strain control mode. The fatigue data have been analysed and elaborated by means of the empirical stiffness reduction approach and the energy ratio method based on the dissipated energy concept.

\section{Materials and Methods}

\subsection{Materials}

2.1.1. Aggregates and Bitumen. The RAP aggregates utilized in the study consist of a waste material obtained from demolition work of highway bituminous pavements, at the conclusion of their service life; such flexible structures were all situated in the Northern Italy and had similar composition. However, also natural aggregates (namely, crushed limestone, sand, and filler) have been used for the production of the hot mix asphalt considered in the laboratory study.

Both types of aggregates were provided by private companies from the Northeastern Italian area. The natural aggregates have been supplied in four different grading fractions: $0 / 4,4 / 8,8 / 12$, and $12 / 20 \mathrm{~mm}$. Figure 1 shows the grading curves of the conventional aggregates (EN 933-1) and that of the RAP material. The grading curve of the RAP has been obtained testing such material after the extraction of the bitumen (white curve, centrifugation method; EN 12697-1).

Three different types of bitumen were employed in the experimental investigation: two bituminous binders modified with SBS (styrene-butadiene-styrene) polymers, along with a conventional, not modified, bitumen. Based on the data provided by the manufacturers, the pair of SBS modified bitumen types are characterized by a different polymer concentration (in the present research the codes "Hard" and "Soft" have been associated with the modified bitumen with the highest and the lowest polymer dosage, respectively).
The major concern related to the use of the RAP material for the production of hot mix asphalt is due to the higher brittleness of the aged RAP binder, which could lead to a worsening of the fatigue performance of the mixes. In order to avoid such issue, soft bitumen can be adopted as a virgin binder to be added to the RAP mixes [23-26]. Nevertheless, some researchers have verified a significant improvement of the fatigue life of RAP mixes, even if low penetration grade bitumen is used, provided that a proper mix design procedure is adopted $[29,30]$.

In this experimental study, the feasibility to go further the concept of high performance recycled hot mix asphalt, using RAP aggregates along with polymer modified bitumen, has been investigated; the aim was to overcome the fatigue performance of the conventional polymer modified asphalt concrete.

2.1.2. Hot Mix Asphalt. Nine different types of hot mix asphalt were considered in the laboratory investigation; each mix has been designed to accomplish the acceptance requisites of base courses asphalt concrete for road pavement.

The conventional bitumen, the soft modified binder, and the hard modified one have been used for the production of three different types of hot mix asphalt, marked with the code CM (conventional mixtures), SM (soft modified), and HM (hard modified), respectively.

Each one of the three types of mixes, in turn includes three different types of asphalt concrete, prepared with an increasing RAP percentage and therefore characterized by a different aggregate structure. The mixes BC/R0, BC/R2, and $\mathrm{BC} / \mathrm{R} 4$ were produced with conventional bitumen and a RAP quantity of $0 \%(\mathrm{R} 0), 20 \%$ (R2), and $40 \%$ (R4), respectively. Similarly, the mixes SM/R0, SM/R2, and SM/R4, as well as $\mathrm{HM} / \mathrm{R} 0, \mathrm{HM} / \mathrm{R} 2$, and HM/R4, were prepared with a RAP content of $0 \%, 20 \%$, and $40 \%$, but utilizing the soft modified binder and the hard one, for the SM mixes and the HM mixtures, respectively. Such experimental programme has been considered to analyse the effect of different types of modified bitumen on the fatigue performance of asphalt concrete made with RAP aggregates. Other researchers have verified the feasibility to produce hot mix asphalt characterized by higher RAP percentages, up to $50 \%[23,25,28,29]$, $60 \%$ [30], and $100 \%[24,26]$; however, for such mixes, it has been recommended to use rejuvenator agents.

In the present investigation it has been decided to avoid the use of such agents, as a consequence of a particular request of the local road agencies (Northeastern area of Italy); therefore, the maximum amount of RAP materials has been fixed at $40 \%$ by weight of the aggregate. Indeed, the present study has been focused on the improvement of the fatigue performance of hot mix asphalt containing significant amount of RAP materials, rather than on increasing the RAP quantity up to very high contents.

\subsection{Methods}

2.2.1. Mix Design Phase. A conventional trial and error procedure [19] was used in order to design the grading curves of the bituminous mixes, optimizing the combination 


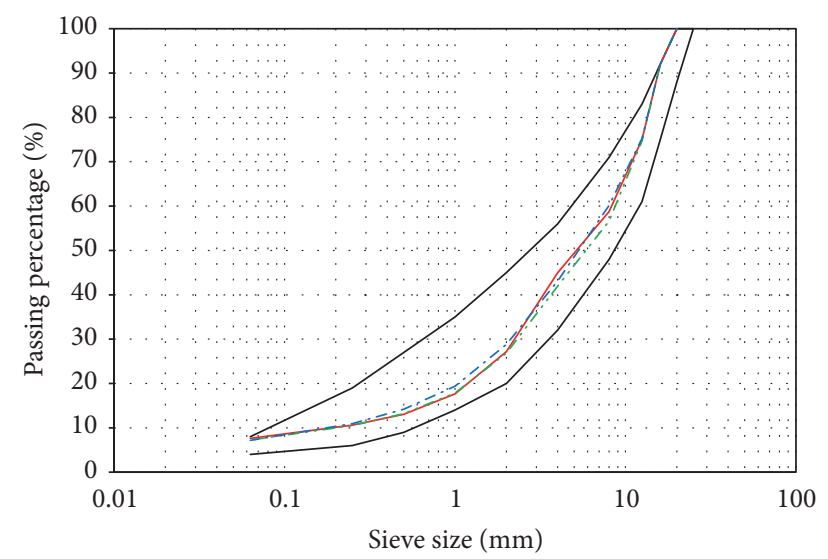

$\begin{array}{ll}(\mathrm{CM} / \mathrm{R} 0-\mathrm{SM} / \mathrm{R} 0-\mathrm{HM} / \mathrm{R} 0) & \cdots(\mathrm{CM} / \mathrm{R} 4-\mathrm{SM} / \mathrm{R} 4-\mathrm{HM} / \mathrm{R} 4) \\ (\mathrm{CM} / \mathrm{R} 2-\mathrm{SM} / \mathrm{R} 2-\mathrm{HM} / \mathrm{R} 2) & \quad \text { Reference envelope }\end{array}$

FIGURE 2: Design grading curves of the hot mix asphalt.

of the particle size with respect to the reference grading envelope for base courses used in the Northeastern Italian area [31]. Figure 2 shows the design grading curves of the mixes referred to the considered reference envelope. The control hot mix asphalt (CM/R0, SM/R0, and HM/R0) has been produced only with limestone aggregates, to allow a proper performance comparison with the mixes made with RAP aggregate.

For each type of hot mix asphalt the design bitumen content (DBC) was determined using an integrated mix design method, based on the volumetric properties and the indirect tensile strength (ITS), with respect to the CIRSItalian Ministry of Infrastructure Specifications [32]. Cylindrical specimens, characterized by a $150 \mathrm{~mm}$ diameter and a $60 \mathrm{~mm}$ height, were prepared for the mix design phase, by means of a gyratory compactor. The key compaction parameters, namely, pressure, speed, and angle of rotation, have been fixed at $600 \mathrm{kPa}, 30$ revs/minute and $1.25^{\circ}$, respectively. The ITS tests were carried out at $25^{\circ} \mathrm{C}$, according to the main indications of EN 12697-23 Standard. Both dry and wet specimens were tested, to determine the stripping resistance of the mixes. The wet specimens were soaked for 15 days in water, using a thermostatic bath. The ratio between the ITS of wet $\left(\right.$ ITS $\left._{\text {wet }}\right)$ and dry $\left(\right.$ ITS $\left._{\text {dry }}\right)$ specimens represents the Tensile Strength Ratio (TSR); such parameter has been determined for each mix investigated.

According to the CIRS design method [32], the volumetric and mechanical acceptance requisites reported in Table 1 have to be satisfied in order to identify the design bitumen content. The volumetric properties, quantified by means of the residual air voids percentage, have been verified at three different compaction levels $(10,100$, and 180 revs), whereas the mechanical resistance was tested at the design number of gyrations (100 revs).

The conventional hypothesis of total blending between the bitumen of RAP and the new virgin binder has been considered in the mix design phase [33]. The DBC regards the new bitumen used for the hot mix asphalt production; therefore, for the mixes prepared with RAP aggregates, the
TABLE 1: Mix design acceptance requisites.

\begin{tabular}{lc}
\hline Parameter & Threshold \\
\hline$V_{a}$ at 10 revs & $10-14 \%$ \\
$V_{a}$ at 100 revs & $3-5 \%$ \\
$V_{a}$ at 180 revs & $>2 \%$ \\
ITS $_{\text {dry }}$ & $>0.6 \mathrm{MPa}$ \\
TSR & $>75 \%$ \\
\hline
\end{tabular}

total bitumen content results are equal to the sum of the DBC and the bitumen of RAP.

The RAP material has been preheated for 2 hours at $90^{\circ} \mathrm{C}$ before being mixed with the limestone and the virgin bitumen, in a heated lab mixer, for one minute.

According to the CIRS specifications [32], the mixing temperatures were $150^{\circ} \mathrm{C}, 160^{\circ} \mathrm{C}$, and $170^{\circ} \mathrm{C}$ for the conventional bitumen, the soft modified binder, and the hard modified one, respectively.

2.2.2. Fatigue Tests. The four-point bending equipment was used for the fatigue investigation, according to the main specifications described in Annex D of the European EN 1269724 Standard; therefore, a continuous sinusoidal waveform, characterized by a frequency of $10 \mathrm{~Hz}$, has been adopted in each test. The bending tests have been performed under the strain control mode, using three different strain levels, within the range $200-600 \mu \mathrm{m} / \mathrm{m}$, in order to properly characterize the fatigue response of each mixture. The fatigue trials were conducted at $20^{\circ} \mathrm{C}$, namely, the most significant temperature to investigate the fatigue performance of asphalt concrete in Italy. The stress and strain data, along with the phase angle and dissipated energy, have been determined by the equipment for each loading cycle. A laboratory compacting roller has been used to prepare slabs $(300 \times 400 \times 50 \mathrm{~mm})$, for each type of asphalt concrete, following the main specifications of the EN 12697-33 Standard. The slabs were subsequently accurately sawed, in order to obtain the beam specimens (400 $\times 50 \times 60 \mathrm{~mm}$ ) required for the fatigue investigation.

Some of the beam specimens were conditioned in an oven at $85^{\circ} \mathrm{C}$ for 5 days [34]; such protocol produces an accelerated long-term ageing, which allows taking into consideration the effect of seasoning on the fatigue resistance of the hot mix asphalt.

The fatigue life of hot mix asphalt is currently determined using primarily the conventional stiffness reduction approach [23-26, 29, 30]. However, such approach relies on the empirical assumption that the fatigue failure of the asphalt specimen occurs at the achieving of the $50 \%$ of the initial stiffness modulus. In the present study the fatigue life has been estimated by means of such empirical approach, in order to allow a comparison with results of previous investigations, but also using the energy ratio approach [35-37], which relies on more rational assumptions.

2.2.3. Stiffness Reduction Approach. In the fatigue test under strain control mode, strain is fixed at a constant value and therefore the stress is continuously decreasing during the test. 
Such reduction, achieved at a high number of loading cycles, down to extremely low values, rarely causes a macrocrack and the complete physical failure of the specimen [38]. Therefore, the conventional failure criterion, largely accepted in the literature, is defined by a $50 \%$ reduction of the initial stiffness [38-41].

In this research, the conventional fatigue curves were determined on the basis of the initial value of strain $\varepsilon_{0}$ and the number of loading repetitions $N_{f}$, at which a $50 \%$ decrement of the initial stiffness is recorded. According to previous relevant studies [42-44], the strain value evaluated at the 100th cycle has been assumed as the initial strain (EN 1269724, Annex D); in fact at this stage of the bending test, the hot mix asphalt specimen is still not damaged and therefore it can be considered in its initial state.

The fatigue data have been interpolated by a power law model, according to the following expression:

$$
\varepsilon_{0}=a N_{f}^{b},
$$

where $a$ and $b$ are interpolation coefficients associated with the type of hot mix asphalt.

2.2.4. Energy Ratio Approach. The conventional failure criteria, even if established by significant changing of the mechanical parameter involved (namely, the stiffness modulus), in comparison to the initial physical state of the sample, are basically empirical and do not reliably describe the condition of internal damage in the hot mix asphalt. In order to achieve a more rational approach, in the study of the fatigue life, Hopman et al. [35] and Pronk [37] proposed a failure criterion related to the energy dissipated during fatigue bending tests, defining the failure condition as the number of cycles $N_{1}$ at which a macrocrack is developed for coalescence of microcracks. Hence, $N_{1}$ is associated with the onset of that macrocrack, which under further loading cycles propagates in the specimen [36]. The use of such failure criterion, for the analysis of the results of fatigue bending tests, permits comparing the fatigue response between mixes in an equivalent damage state, related to the onset of macrocracks. Such criterion is recognized in the literature as more physically significant and reliable [37]. From the analytical point of view, this approach is based on the definition of the energy ratio $R_{n}$, computed as the ratio between the energy dissipated from the beginning of the test, up to the $n$th cycle and that dissipated at the $n$th cycle:

$$
R_{n}=\frac{\pi \sum_{i=0}^{n} \sigma_{i} \varepsilon_{i} \sin \phi_{i}}{\pi \sigma_{n} \varepsilon_{n} \sin \phi_{n}}
$$

where $\sigma$ represents the stress, $\varepsilon$ the strain, $\phi$ the phase angle, $i$ the generic $i$ th cycle, and $n$ the $n$th cycle. In order to identify $N_{1}$, the evolution of the energy ratio with respect to the number of cycles has to be accurately studied. With regard to the strain control mode, $N_{1}$ can be identified in correspondence with the experimental point in the $R_{n}$ curve, at which a nonlinear trend is detected. Instead, the identification of $N_{1}$ for the stress control mode is associated with the achievement of the peak point of the $R_{n}$ curve. Artamendi

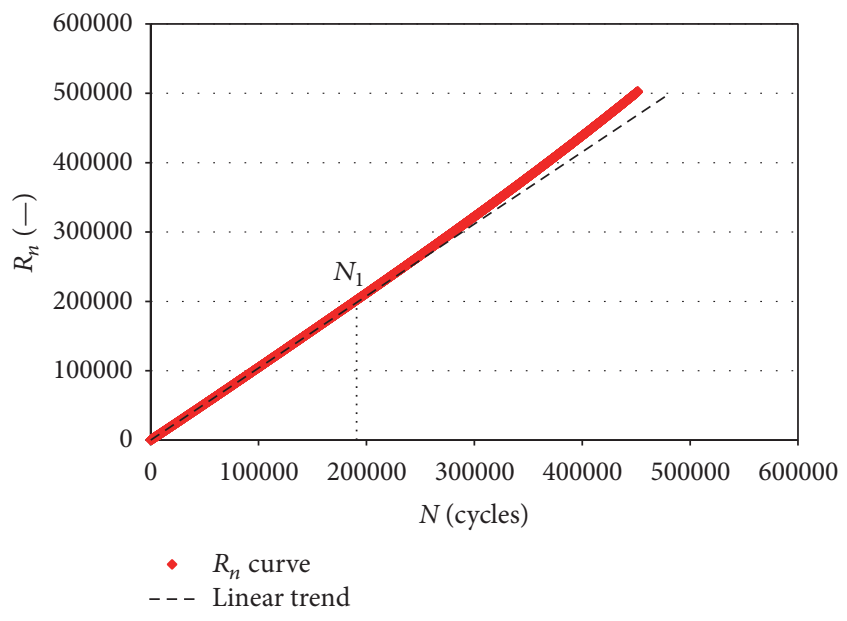

Figure 3: Determination of $N_{1}$ for mix HM/R2 at $400 \mu \mathrm{m} / \mathrm{m}$.

and Khalid [42] have already discussed the subjectivity of the $N_{1}$ identification procedure, for the strain control tests. Figure 3 represents a typical example, for the mix HM/R2, of the $N_{1}$ identification in case of controlled strain. The accurate identification of such number of cycles, $N_{1}$, is potentially affected by the subjectivity of the researcher.

In a similar way to that followed with the empirical approach, it is possible to elaborate new fatigue curves, using a power model as that of (1), introducing the $N_{1}$ concept in substitution of the empirical $N_{f}$.

\section{Results and Discussion}

3.1. Materials Characterization. The particle morphology of the aggregates has been characterized in terms of Flakiness Index (EN 933-3). The results were within the range 7-10\% for the limestone, depending on the particle size; instead, a value equal to $8 \%$ was obtained for the RAP. The mechanical resistance of the aggregates was verified by means of the Los Angeles test (EN 1097-2), which has outlined similar results for the different materials: $23 \%$ for the natural aggregates (4/8 mm fraction) and $25 \%$ for RAP. Finally, the particle density of the aggregates was evaluated (EN 1097-6); values within the range $2.784-2.790 \mathrm{Mg} / \mathrm{m}^{3}$ have been determined for the natural aggregates, whereas the RAP has presented a lower value, equal to $2.746 \mathrm{Mg} / \mathrm{m}^{3}$.

The cold extraction test, carried out on the RAP, has outlined a bitumen percentage of $5.3 \%$ by weight of the aggregate. The bituminous binder of the RAP has been recovered using the ABSON method (EN 12697-3) and then characterized in terms of penetration at $25^{\circ} \mathrm{C}$ (EN 1426), softening point (Ring \& Ball Method; EN 1427), Fraass breaking point (EN 12593), and viscosity at $160^{\circ} \mathrm{C}$ (EN 13702-2); the results are presented in Table 2 , along with the values obtained for the conventional bitumen and the polymer modified binders.

According to the experimental data reported in Table 2, the RAP bitumen can be considered very aged and hard. Both the polymer modified binders presented lower penetration, as well as higher values for the softening point and the viscosity, 
TABLE 2: Bitumen characterization.

\begin{tabular}{|c|c|c|c|c|c|}
\hline Properties & Standard & RAP binder & Conventional bitumen & Hard modified & Soft modified \\
\hline Penetration $(0.1 \times \mathrm{mm}), 100 \mathrm{~g}, 5 \mathrm{~s}$ at $25^{\circ} \mathrm{C}$ & EN 1426 & 18 & 52 & 43 & 50 \\
\hline Softening point $\left({ }^{\circ} \mathrm{C}\right), \mathrm{R} \& \mathrm{~B}$ method & EN 1427 & 64 & 48 & 98 & 92 \\
\hline Fraass breaking point $\left({ }^{\circ} \mathrm{C}\right)$ & EN 12593 & - & -18 & -18 & -19 \\
\hline Viscosity at $160^{\circ} \mathrm{C}$ & UNI EN 13702-2 & 0.256 & 0.13 & 1.33 & 0.62 \\
\hline
\end{tabular}

TABle 3: Aggregate composition of the hot mix asphalt.

\begin{tabular}{|c|c|c|c|c|c|c|c|c|c|c|}
\hline \multirow{2}{*}{ Aggregate type } & \multirow{2}{*}{ Fraction $(\mathrm{mm})$} & \multicolumn{9}{|c|}{ Hot mix asphalt } \\
\hline & & $\mathrm{CM} / \mathrm{R} 0$ & $\mathrm{CM} / \mathrm{R} 2$ & $\mathrm{CM} / \mathrm{R} 4$ & $\mathrm{HM} / \mathrm{R} 0$ & HM/R2 & $\mathrm{HM} / \mathrm{R} 4$ & SM/R0 & $\mathrm{SM} / \mathrm{R} 2$ & $\mathrm{SM} / \mathrm{R} 4$ \\
\hline Sand & $0 / 4$ & 47 & 25 & 8 & 47 & 25 & 8 & 47 & 25 & 8 \\
\hline Limestone & $4 / 8$ & 7 & 9 & 12 & 7 & 9 & 12 & 7 & 9 & 12 \\
\hline Limestone & $8 / 12$ & 7 & 9 & 5 & 7 & 9 & 5 & 7 & 9 & 5 \\
\hline Limestone & $12 / 20$ & 34 & 34 & 34 & 34 & 34 & 34 & 34 & 34 & 34 \\
\hline Filler & - & 5 & 3 & 1 & 5 & 3 & 1 & 5 & 3 & 1 \\
\hline RAP & $0 / 4$ & 0 & 20 & 40 & 0 & 20 & 40 & 0 & 20 & 40 \\
\hline
\end{tabular}

TABLE 4: Physical and mechanical properties of the hot mix asphalt.

\begin{tabular}{|c|c|c|c|c|c|c|c|c|}
\hline $\begin{array}{l}\text { Asphalt } \\
\text { concrete }\end{array}$ & $\mathrm{DBC}(\%)$ & Va, 10 revs (\%) & $\mathrm{Va}, 100$ revs (\%) & Va, 180 revs (\%) & Bulk density $\left(\mathrm{Mg} / \mathrm{m}^{3}\right)$ & ITS dry (MPa) & ITS wet $(\mathrm{MPa})$ & TSR (\%) \\
\hline $\mathrm{CM} / \mathrm{R} 0$ & 5.00 & 13.9 & 4.9 & 3.4 & 2.457 & 1.04 & 0.89 & 86 \\
\hline $\mathrm{CM} / \mathrm{R} 2$ & 3.94 & 13.6 & 4.5 & 3.3 & 2.473 & 1.54 & 1.36 & 88 \\
\hline $\mathrm{CM} / \mathrm{R} 4$ & 2.88 & 11.2 & 3.5 & 2.3 & 2.484 & 1.95 & 1.78 & 91 \\
\hline $\mathrm{SM} / \mathrm{R} 0$ & 5.00 & 14.0 & 4.9 & 3.6 & 2.455 & 1.23 & 1.08 & 88 \\
\hline SM/R2 & 3.94 & 13.9 & 4.7 & 3.5 & 2.470 & 1.67 & 1.50 & 90 \\
\hline $\mathrm{SM} / \mathrm{R} 4$ & 2.88 & 11.4 & 3.6 & 2.4 & 2.480 & 2.19 & 1.97 & 90 \\
\hline HM/R0 & 5.00 & 14.0 & 5.0 & 3.8 & 2.451 & 1.62 & 1.46 & 90 \\
\hline $\mathrm{HM} / \mathrm{R} 2$ & 3.94 & 13.8 & 4.8 & 3.7 & 2.465 & 2.08 & 1.92 & 92 \\
\hline $\mathrm{HM} / \mathrm{R} 4$ & 2.88 & 11.3 & 3.8 & 2.6 & 2.477 & 2.32 & 2.16 & 93 \\
\hline
\end{tabular}

compared to the conventional bitumen. The hard modified bitumen was characterized by the highest viscosity.

3.2. Mix Design Results. Table 3 reports the aggregate structure of the hot mix asphalt considered in the study.

For each type of bitumen used in the investigation, three different aggregate compositions have been designed. The greater the RAP quantity, the lower the filler percentage that is needed in order to optimize the mix. Each mix is characterized by the same amount of the coarser limestone grains, namely, the fraction $12 / 20$. Instead, for the other two limestone fractions $(4 / 8$ and $8 / 12 \mathrm{~mm})$, the contents are different, depending on the RAP percentage.

The results of the mix design phase are summarised in Table 4. For each type of hot mix asphalt studied, the most relevant properties are presented: DBC (by weight of the aggregate); air voids (Va) at 10, 100, and 180 revs; bulk density at 100 revs; indirect tensile strength (ITS) for dry and wet conditions, at 100 revs.

The bitumen percentage shown in Table 4 represents the virgin binder used in order to optimize the hot mix asphalt.

For all the mixes, the air voids requisites prescribed by CIRS mix design procedure [32] have been totally satisfied, depending on the specific DBC. The dry ITS and TSR resulted in much higher values than the CIRS requisites, for all the hot mix asphalt. Even the wet ITS values were always greater than the dry ITS requirement, so demonstrating a very good moisture resistance of the designed mixes.

The total bitumen contents resulted within the range usually used for base courses, namely, 4.5-5.5\% by weight of the aggregate [32], for all the hot mix asphalt. As it was expected, the greater the RAP amount used in the mix, the smaller the new bitumen content necessary to fulfil the CIRS requirements; such laboratory data are consistent with the hypothesis of a complete blending between RAP bitumen and new binder.

No workability difficulties were noted during the mixing phase, neither for the compaction of the hot mix asphalt made with RAP, independently from the type of binder.

3.3. Fatigue Analysis Based on the Stiffness Reduction Approach. Based on the stiffness reduction approach, the elaboration of the fatigue data has allowed obtaining the fatigue curves shown in Figures 4 and 5, for the unaged and aged hot mix asphalt, respectively. The regression coefficients 


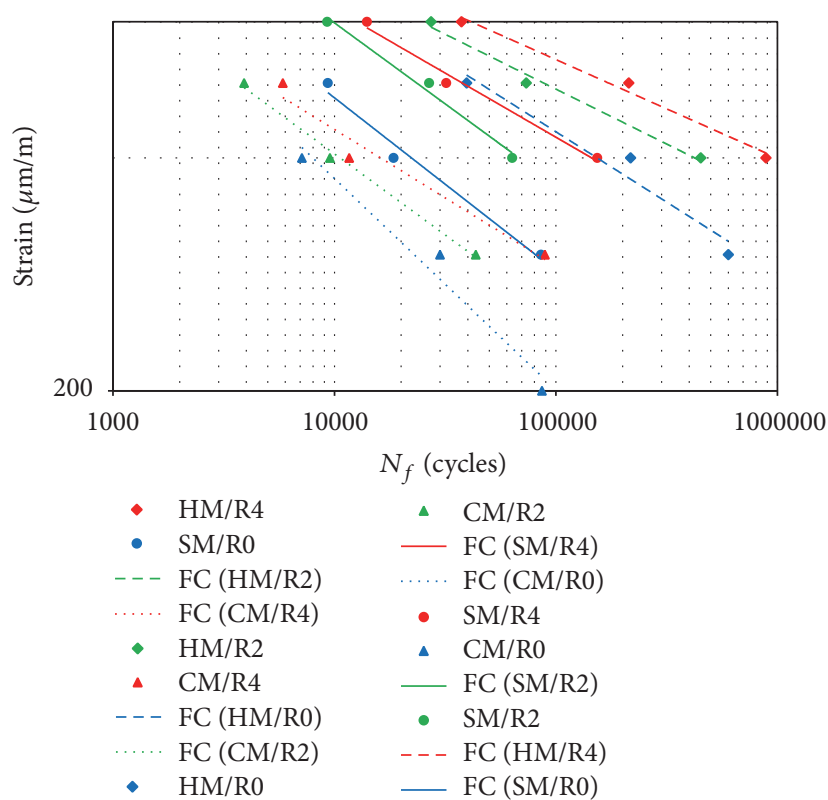

Figure 4: Fatigue life $N_{f}$ versus initial strain: unaged mixes.

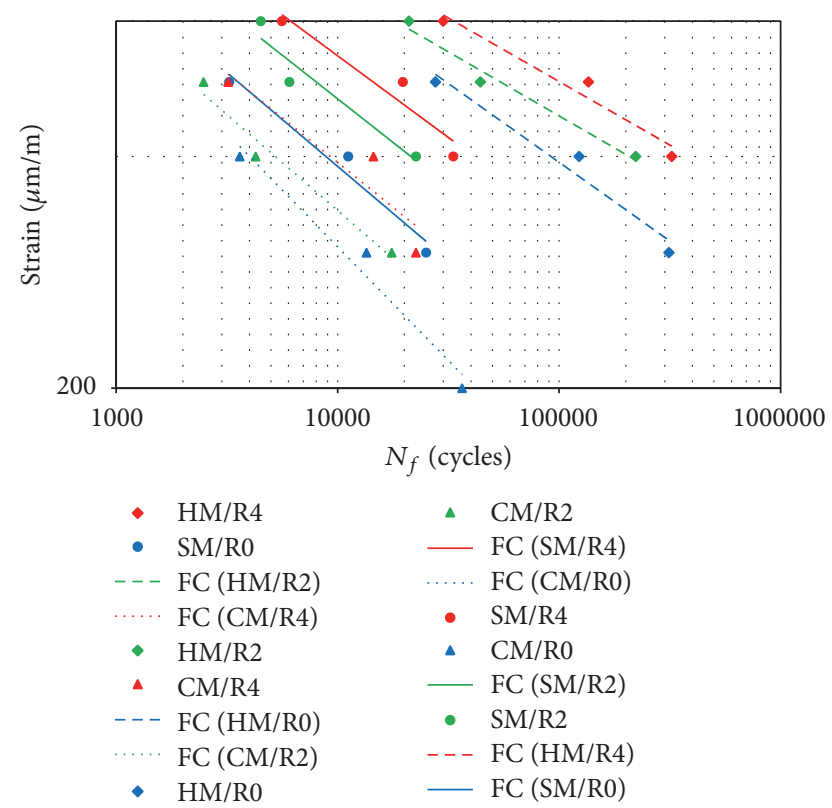

FIgURE 5: Fatigue life $N_{f}$ versus initial strain: aged mixes.

and the coefficient of determination $R^{2}$ are reported in Tables 5 and 6 . The tensile strain associated with a fatigue resistance of 1,000,000 loading repetitions, namely, $\varepsilon\left(10^{6}\right)$, has been calculated according to the indications of the Standard EN 12697-24, Annex D.

As it was expected, the mixes produced with the polymer modified binders, especially in case of the hard one, have shown a fatigue life much higher than that of the hot mix asphalt made with the conventional bitumen, independently of the RAP percentage. In fact, the fatigue curves of the polymer modified mixes are characterized by a lower slope
TABLE 5: Regression coefficients of the fatigue curves: $N_{f}$ approach for unaged mixtures.

\begin{tabular}{lcccc}
\hline Mixture & $a(\mu \mathrm{m} / \mathrm{m})$ & $b(-)$ & $\varepsilon\left(10^{6}\right)(\mu \mathrm{m} / \mathrm{m})$ & $R^{2}(-)$ \\
\hline $\mathrm{CM} / \mathrm{R} 0$ & 4658.4 & -0.273 & 107 & 0.9661 \\
$\mathrm{CM} / \mathrm{R} 2$ & 2793.9 & -0.210 & 154 & 0.9943 \\
$\mathrm{CM} / \mathrm{R} 4$ & 2221.2 & -0.177 & 193 & 0.9587 \\
$\mathrm{SM} / \mathrm{R} 0$ & 3741.8 & -0.223 & 172 & 0.9791 \\
$\mathrm{SM} / \mathrm{R} 2$ & 4113.8 & -0.209 & 229 & 0.9864 \\
$\mathrm{SM} / \mathrm{R} 4$ & 2866.5 & -0.166 & 289 & 0.9858 \\
$\mathrm{HM} / \mathrm{R} 0$ & 3508.2 & -0.182 & 284 & 0.953 \\
$\mathrm{HM} / \mathrm{R} 2$ & 2515.0 & -0.142 & 364 & 0.9880 \\
$\mathrm{HM} / \mathrm{R} 4$ & 2322.1 & -0.127 & 402 & 0.9867 \\
\hline
\end{tabular}

TABLE 6: Regression coefficients of the fatigue curves: $N_{f}$ approach for aged mixtures.

\begin{tabular}{lcccc}
\hline Mixture & $a(\mu \mathrm{m} / \mathrm{m})$ & $b(-)$ & $\varepsilon\left(10^{6}\right)(\mu \mathrm{m} / \mathrm{m})$ & $R^{2}(-)$ \\
\hline CM/R0 & 4638.4 & -0.295 & 79 & 0.9685 \\
CM/R2 & 3388.0 & -0.250 & 107 & 0.9679 \\
CM/R4 & 3340.2 & -0.232 & 135 & 0.8637 \\
SM/R0 & 3670.4 & -0.244 & 126 & 0.9632 \\
SM/R2 & 3835.8 & -0.227 & 167 & 0.9176 \\
SM/R4 & 3821.9 & -0.212 & 204 & 0.9171 \\
HM/R0 & 4155.0 & -0.205 & 245 & 0.9582 \\
HM/R2 & 3069.6 & -0.166 & 310 & 0.9768 \\
HM/R4 & 3351.3 & -0.165 & 343 & 0.9550 \\
\hline
\end{tabular}

and, moreover, they are shifted towards higher loading cycles values (Tables 5 and 6). Then, it is possible to observe the higher tensile strain $\varepsilon\left(10^{6}\right)$ obtained for the RAP mixes, particularly for the greater RAP content $(40 \%)$; such response has been observed for all the binders used in the investigation (Tables 5 and 6).

Hence, the use of the polymer modified binders, rather than RAP, considering each of them individually, enhances the fatigue life of the mixes. Nevertheless, the achievement of the highest fatigue resistance is feasible only using simultaneously the modified binders along with the greater RAP percentage. The highest fatigue life, $402 \mu \mathrm{m} / \mathrm{m}$, was obtained for HM/R4 (Table 5). Such value is much higher (42\%) than that determined for the control mix produced with natural materials (HM/R0). However, the increase in the fatigue resistance, associated with the utilization of RAP aggregates, has been nonlinear with the RAP quantity; in fact the improvement was higher using the $40 \%$ of RAP rather than the $20 \%$.

This general trend can be observed also for the aged hot mix asphalt (Table 6). However, as it was expected [11], the ageing process reduces the fatigue life of all the mixes.

3.4. Fatigue Analysis Based on the Energy Ratio Approach. Figures 6 and 7 show the fatigue curves processed on the basis of the energy ratio approach, for the unaged and aged hot mix asphalt, respectively. Tables 7 and 8 present the coefficients 
TABLE 7: Regression coefficients of the fatigue curves: $N_{1}$ approach for unaged mixtures.

\begin{tabular}{lcccc}
\hline Mixture & $a(\mu \mathrm{m} / \mathrm{m})$ & $b(-)$ & $\varepsilon\left(10^{6}\right)(\mu \mathrm{m} / \mathrm{m})$ & $R^{2}(-)$ \\
\hline CM/R0 & 3315.6 & -0.254 & 99 & 0.9809 \\
CM/R2 & 3081.3 & -0.227 & 134 & 0.9923 \\
CM/R4 & 2552.4 & -0.195 & 173 & 0.9978 \\
SM/R0 & 4160.3 & -0.242 & 147 & 0.9763 \\
SM/R2 & 3166.5 & -0.197 & 208 & 0.9750 \\
SM/R4 & 2811.0 & -0.172 & 261 & 0.9849 \\
HM/R0 & 4359.3 & -0.207 & 250 & 0.9763 \\
HM/R2 & 2902.9 & -0.162 & 310 & 09841 \\
HM/R4 & 2362.3 & -0.135 & 366 & 0.9949 \\
\hline
\end{tabular}

TABLE 8: Regression coefficients of the fatigue curves: $N_{1}$ approach for aged mixtures.

\begin{tabular}{lcccc}
\hline Mixture & $a(\mu \mathrm{m} / \mathrm{m})$ & $b(-)$ & $\varepsilon\left(10^{6}\right)(\mu \mathrm{m} / \mathrm{m})$ & $R^{2}(-)$ \\
\hline $\mathrm{CM} / \mathrm{R} 0$ & 2984.6 & -0.267 & 75 & 0.9528 \\
$\mathrm{CM} / \mathrm{R} 2$ & 2936.7 & -0.248 & 95 & 0.9782 \\
$\mathrm{CM} / \mathrm{R} 4$ & 3016.8 & -0.233 & 121 & 0.9216 \\
$\mathrm{SM} / \mathrm{R} 0$ & 3599.2 & -0.250 & 114 & 0.9968 \\
$\mathrm{SM} / \mathrm{R} 2$ & 2918.9 & -0.214 & 152 & 0.9501 \\
$\mathrm{SM} / \mathrm{R} 4$ & 2761.8 & -0.195 & 187 & 0.9306 \\
$\mathrm{HM} / \mathrm{R} 0$ & 4631.1 & -0.221 & 219 & 0.9951 \\
$\mathrm{HM} / \mathrm{R} 2$ & 3280.9 & -0.182 & 265 & 0.9986 \\
$\mathrm{HM} / \mathrm{R} 4$ & 3165.5 & -0.168 & 311 & 0.9964 \\
\hline
\end{tabular}

of interpolation and determination, along with the value of $\varepsilon$ $\left(10^{6}\right)$.

Even if the comparison of values of $\varepsilon\left(10^{6}\right)$ associated with the various asphalt concrete, by means of the empirical method and the energy ratio approach [37] leads to an analogous ranking of the mixes, it can be noted that the analysis of the fatigue data with the energy ratio method outlines a more conservative evaluation of the fatigue resistance of the hot mix asphalt. In fact, the values of tensile strain for $1,000,000$ loading repetitions, computed using the energy ratio approach, are lower than those determined by means of the empirical method.

Compared to the control bituminous mixtures (CM/R0, SM/R0 and HM/R0), the hot mix asphalt produced with RAP aggregates was characterized by higher $\varepsilon\left(10^{6}\right)$ values; improvements from $35 \%$ to $74 \%$ in case of standard bitumen, from $42 \%$ to $78 \%$ using the soft polymer modified binder, and from $24 \%$ to $47 \%$ with the hard one have been obtained, depending on the RAP percentage. The highest fatigue life, independently of the type of bitumen, was obtained for the hot mix asphalt prepared with 40\% RAP (CM/R4, SM/R4 and HM/R4).

The improved fatigue resistance presented by the RAP mixes (Tables 7 and 8) could be due to the good affinity between the bitumen added to the mixes (both the modified and the standard one) and that of RAP; such affinity probably allows very strong adhesion between the thin film of virgin binder and the RAP grains. Improved fatigue behaviour

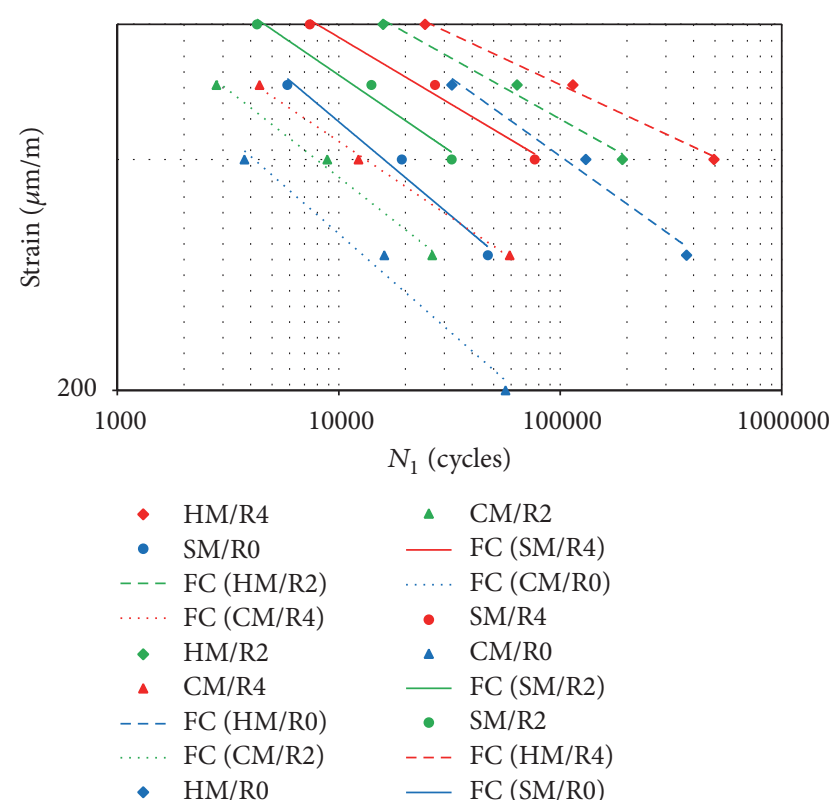

FIGURE 6: Fatigue life $N_{1}$ versus initial strain: unaged mixes.

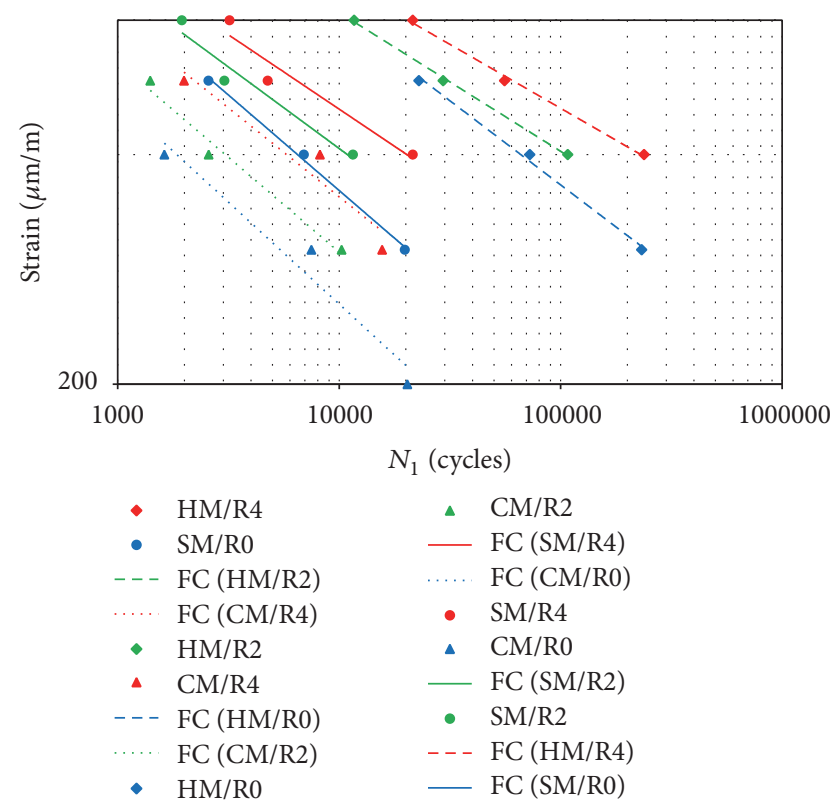

FIgURE 7: Fatigue life $N_{1}$ versus initial strain: aged mixes.

for RAP mixtures has been already documented by other research groups $[14,24]$. They have considered the RAP particles and the virgin bitumen as a layered system in which the aged binder of the RAP assumes the role of an intermediate stiff layer between the stiffer lithic grains of the RAP and the softer new bitumen that coats the RAP particles. On the basis of such assumption, the aged binder of the RAP allows reducing the stress concentration within the hot mix asphalt, which in turn improves the fatigue life.

Nevertheless, the greater $\varepsilon\left(10^{6}\right)$ values were achieved by the mixes produced with RAP and polymer modified binders; 
the highest fatigue life has been obtained by HM/R4. Such additional increment of the fatigue life determined for the RAP mixtures prepared with PMB could be justified by the flexibility given by the polymers of the modified binders.

According to the CIRS technical specifications [32], the greatest RAP percentage admissible for road base hot mix asphalt is up to $30 \%$; furthermore, the use of a polymer modified bitumen is not taken in consideration for RAP mixtures. Hence, the feasibility to produce hot mix asphalt with significant RAP content (up to $40 \%$ ), characterized by a fatigue life greater than that of high performance polymer modified bituminous mixtures, made with limestone materials, can be considered one step further towards sustainability and high resistance to loading cycles, in the Italian road pavement technology.

According to the results of the current study, the RAP effect on the fatigue resistance of the asphalt concrete analysed can be evaluated very positively; however, a straight generalization of such experimental results has to be very carefully considered. Indeed, the integration of such waste material in the structure of a bituminous mixture is very challenging, in relation to some important elements, for example, the RAP particle size distribution, the RAP bitumen percentage and its ageing state, the particular type of hot mix asphalt being investigated, and the rheological properties of the new binder to be added to the mixture.

The ranking of the mixes, in terms of fatigue life, has been completely confirmed also for the hot mix asphalt which underwent the accelerated ageing process (Table 8), as already observed with the empirical approach; it is still the mix $\mathrm{HM} / \mathrm{R} 4$ to achieve the highest fatigue life, in terms of $\varepsilon\left(10^{6}\right)$ values $(311 \mu \mathrm{m} / \mathrm{m})$. Nevertheless, it can be noticed that the higher the RAP content, the greater the fatigue life reduction due to the ageing phenomenon, which affects the ductility of the mixes; such reduction falls within the range from $12 \%$ to $30 \%$, depending on the RAP content and the type of bitumen. However, for each type of binder, the reductions in the fatigue life due to ageing were very similar between the mixes with $40 \%$ RAP and those made with $20 \%$ RAP. For instance, for the hard modified mixtures, such reductions were equal to $15 \%$ and $14 \%$, at $40 \%$ RAP and $20 \%$ RAP, respectively.

Instead, the type of binder affects noticeably the fatigue life reduction; in fact, it can be observed that for the hard modified mixes, the ageing produces lower detrimental effects (up to 15\%), with respect to the soft modified asphalt (up to $28 \%$ ) and the unmodified mixtures (up to $30 \%$ ). Probably the polymer modification of the bitumen allows guaranteeing better ductility of the mixes.

\section{Conclusions}

The experimental study described in the present paper discusses the fatigue performance of hot mix asphalt for road base courses produced with RAP and polymer modified binders.

The fatigue data, obtained by means of four-point bending tests carried out at $10 \mathrm{~Hz}$ and $20^{\circ} \mathrm{C}$, under strain control mode, have been analysed according to both the conventional stiffness reduction approach and the energy ratio method; the latter focused on the dissipated energy concept.

Compared to the control mixes, prepared with a full limestone aggregate structure, the hot mix asphalt containing RAP has presented higher resistance to loading cycles, especially at 40\% RAP, also under postageing conditions.

The improvements in the fatigue life observed for the RAP mixes have been even more relevant using the polymer modified binders, particularly in the case of the hard modified one.

Although the experimental fatigue data have outlined an extremely positive effect of RAP on the fatigue performance of the hot mix asphalt tested, a broad generalization of the RAP influence to different asphalt concrete has to be very carefully taken in consideration.

The fatigue analysis conducted using the empirical approach and the energy ratio method has led to the same qualitative ranking of the mixes considered; however quantitative differences have been observed that cannot be neglected.

The energy ratio approach has identified a fatigue life that has been always lower than that determined by the empirical method, for all the cases studied; therefore, the conventional stiffness reduction approach should be carefully used to avoid an overestimation of the fatigue resistance of the mixes.

The ageing phenomenon affects the fatigue performance of all the hot mix asphalt involved, particularly those prepared with RAP and conventional bitumen; however a modification from $20 \%$ to $40 \%$ RAP in the aggregate structure involves just a small reduction of the fatigue life (about $1 \%$, in terms of $\varepsilon$ $\left(10^{6}\right)$ values).

\section{Competing Interests}

The authors declare that they have no conflict of interest.

\section{References}

[1] W. Cao, "Study on properties of recycled tire rubber modified asphalt mixtures using dry process," Construction and Building Materials, vol. 21, no. 5, pp. 1011-1015, 2007.

[2] C.-T. Chiu and L.-C. Lu, "A laboratory study on stone matrix asphalt using ground tire rubber," Construction and Building Materials, vol. 21, no. 5, pp. 1027-1033, 2007.

[3] Y. Liu, S. Han, Z. Zhang, and O. Xu, "Design and evaluation of gap-graded asphalt rubber mixtures," Materials and Design, vol. 35, pp. 873-877, 2012.

[4] C. C. Wong and W.-G. Wong, "Effect of crumb rubber modifiers on high temperature susceptibility of wearing course mixtures," Construction and Building Materials, vol. 21, no. 8, pp. 1741-1745, 2007.

[5] N. Ali, S. Zahran, J. Trogdon, and A. Bergan, "A mechanistic evaluation of modified asphalt paving mixtures," Canadian Journal of Civil Engineering, vol. 21, no. 6, pp. 954-965, 1994.

[6] Y. Becker, M. P. Méndez, and Y. Rodríguez, "Polymer modified asphalt," Vision Tecnologica, vol. 9, no. 1, pp. 39-50, 2001.

[7] U. Isacsson and X. Lu, "Testing and appraisal of polymer modified road bitumens-state of the art," Materials and Structures, vol. 28, no. 3, pp. 139-159, 1995. 
[8] B. V. Kök and H. Colak, "Laboratory comparison of the crumb-rubber and SBS modified bitumen and hot mix asphalt," Construction and Building Materials, vol. 25, no. 8, pp. 32043212, 2011.

[9] A. Othman, L. Figueroa, and H. Aglan, "Fatigue behavior of styrene-butadiene-styrene modified asphaltic mixtures exposed to low-temperature cyclic aging," Transportation Research Record, no. 1492, pp. 129-134, 1995.

[10] H. Özen, A. Aksoy, S. Tayfur, and F. Çelik, "Laboratory performance comparison of the elastomer-modified asphalt mixtures," Building and Environment, vol. 43, no. 7, pp. 12701277, 2008.

[11] P. Marco and B. Nicola, "Fatigue performance of asphalt concretes made with steel slags and modified bituminous binders," International Journal of Pavement Research and Technology, vol. 6, no. 4, pp. 294-303, 2013.

[12] P. Ahmedzade and B. Sengoz, "Evaluation of steel slag coarse aggregate in hot mix asphalt concrete," Journal of Hazardous Materials, vol. 165, no. 1-3, pp. 300-305, 2009.

[13] B. A. Asmatulaev, R. B. Asmatulaev, A. S. Abdrasulova, B. L. Levintov, M. F. Vitushchenko, and O. A. Stolyarskiiv, "Using blast-furnace slag in road construction," Steel in Translation, vol. 37, no. 8, pp. 722-725, 2007.

[14] B. Huang, G. Li, D. Vukosavljevic, X. Shu, and B. K. Egan, "Laboratory investigation of mixing hot-mix asphalt with reclaimed asphalt pavement," Transportation Research Record, no. 1929, pp. 37-45, 2005.

[15] A. Kavussi and M. J. Qazizadeh, "Fatigue characterization of asphalt mixes containing electric arc furnace (EAF) steel slag subjected to long term aging," Construction and Building Materials, vol. 72, pp. 158-166, 2014.

[16] E. A. Oluwasola, M. R. Hainin, and M. M. A. Aziz, "Evaluation of asphalt mixtures incorporating electric arc furnace steel slag and copper mine tailings for road construction," Transportation Geotechnics, vol. 2, pp. 47-55, 2015.

[17] M. Pasetto and N. Baldo, "Fatigue performance of asphalt concretes with RAP aggregates and steel slags," in Proceedings of the 7th RILEM International Conference on Cracking in Pavements, vol. 4, pp. 719-727, RILEM Bookseries, Delft, Netherlands, 2012.

[18] M. Pasetto and N. Baldo, "Resistance to permanent deformation of road and airport high performance asphalt concrete base courses," Advanced Materials Research, vol. 723, pp. 494-502, 2013.

[19] M. Pasetto and N. Baldo, "Influence of the aggregate skeleton design method on the permanent deformation resistance of stone mastic asphalt," Materials Research Innovations, vol. 18, no. 3, pp. S96-S101, 2014.

[20] Y. Xue, S. Wu, H. Hou, and J. Zha, "Experimental investigation of basic oxygen furnace slag used as aggregate in asphalt mixture," Journal of Hazardous Materials, vol. 138, no. 2, pp. 261268, 2006.

[21] Y. Xue, H. Hou, S. Zhu, and J. Zha, "Utilization of municipal solid waste incineration ash in stone mastic asphalt mixture: pavement performance and environmental impact," Construction and Building Materials, vol. 23, no. 2, pp. 989-996, 2009.

[22] S. Wu, Y. Xue, Q. Ye, and Y. Chen, "Utilization of steel slag as aggregates for stone mastic asphalt (SMA) mixtures," Building and Environment, vol. 42, no. 7, pp. 2580-2585, 2007.

[23] C. Celauro, C. Bernardo, and B. Gabriele, "Production of innovative, recycled and high-performance asphalt for road pavements," Resources, Conservation and Recycling, vol. 54, no. 6, pp. 337-347, 2010.
[24] J. R. M. Oliveira, H. M. R. D. Silva, C. M. G. Jesus, L. P. F. Abreu, and S. R. M. Fernandes, "Pushing the asphalt recycling technology to the limit," International Journal of Pavement Research and Technology, vol. 6, no. 2, pp. 109-116, 2013.

[25] P. A. A. Pereira, J. R. M. Oliveira, and L. G. Picado-Santos, "Mechanical characterisation of hot mix recycled materials," International Journal of Pavement Engineering, vol. 5, no. 4, pp. 211-220, 2004.

[26] H. M. R. D. Silva, J. R. M. Oliveira, and C. M. G. Jesus, "Are totally recycled hot mix asphalts a sustainable alternative for road paving?" Resources, Conservation and Recycling, vol. 60, pp. 38-48, 2012.

[27] A. Stimilli, A. Virgili, F. Giuliani, and F. Canestrari, "In plant production of hot recycled mixtures with high reclaimed asphalt pavement content: a performance evaluation in," in Proceedings of the 8th RILEM International Symposium on Testing and Characterization of Sustainable and Innovative Bituminous Materials, vol. 11, pp. 927-939, RILEM Bookseries, Ancona, Italy, 2016.

[28] B. Colbert and Z. You, "The determination of mechanical performance of laboratory produced hot mix asphalt mixtures using controlled RAP and virgin aggregate size fractions," Construction and Building Materials, vol. 26, no. 1, pp. 655-662, 2012.

[29] R. Miró, G. Valdés, A. Martínez, P. Segura, and C. Rodríguez, "Evaluation of high modulus mixture behaviour with high reclaimed asphalt pavement (RAP) percentages for sustainable road construction," Construction and Building Materials, vol. 25, no. 10, pp. 3854-3862, 2011.

[30] G. Valdés, F. Pérez-Jiménez, R. Miró, A. Martínez, and R. Botella, "Experimental study of recycled asphalt mixtures with high percentages of reclaimed asphalt pavement (RAP)," Construction and Building Materials, vol. 25, no. 3, pp. 1289-1297, 2011.

[31] Capitolato Speciale d'Appalto Tipo per la Manutenzione e la Costruzione delle Infrastrutture Stradali, Veneto Strade, Venezia, Italy, 2012 (Italian).

[32] CIRS-Ministero delle Infrastrutture e dei Trasporti, Capitolato Speciale d'Appalto Tipo per Lavori Stradali, CIRS-Ministero delle Infrastrutture e dei Trasporti, Italy, 2001 (Italian).

[33] I. L. Al-Qadi, M. Elseifi, and S. H. Carpenter, "Reclaimed asphalt pavement-a literature review," Tech. Rep. FHWA-ICT-07-001, Federal Highway Administration ( FHWA), Washington, DC, USA, 2007

[34] I. Artamendi, B. Allen, and P. Phillips, "Influence of temperature and aging on laboratory fatigue performance of asphalt mixtures," in Proceedings of the Advanced Testing and Characterization of Bituminous Materials Conference, pp. 185-194, Rhodes, Greece, 2009.

[35] P. C. Hopman, P. A. Kunst, and A. C. Pronk, "A renew interpretation method for fatigue measurements, verification of Miner's rule," in Proceedings of the 4th Eurobitume Symposium, Madrid, Spain, 1989.

[36] G. M. Rowe, "Performance of asphalt mixtures in the trapezoidal fatigue test," Journal of Association of Asphalt Paving Technologists, vol. 62, pp. 344-384, 1993.

[37] A. C. Pronk, "Comparison of 2 and 4 point fatigue tests and healing in 4 point dynamic test based on the dissipated energy concept," in Proceedings of the 8th International Conference on Asphalt Pavement, vol. 2 and 4, Seattle, Wash, USA, 1997. 
[38] H. A. Khalid, "Comparison between bending and diametral fatigue tests for bituminous materials," Materials and Structures/Materiaux et Constructions, vol. 33, no. 231, pp. 457-465, 2000.

[39] W. Van Dijk and W. Visser, "The energy approach to fatigue for pavement design," Journal of Association of Asphalt Paving Technologists, vol. 46, pp. 1-40, 1977.

[40] A. A. Tayebali, G. M. Rowe, and J. B. Sousa, "Fatigue response of asphalt-aggregate mixtures," Journal of Association of Asphalt Paving Technologists, vol. 61, pp. 333-360, 1992.

[41] K. A. Ghuzlan and S. H. Carpenter, "Traditional fatigue analysis of asphalt concrete mixtures," in Proceedings of the Transportation Research Board Annual Meeting, Washington, DC, USA, January 2003.

[42] I. Artamendi and H. Khalid, "Characterization of fatigue damage for paving asphaltic materials," Fatigue and Fracture of Engineering Materials and Structures, vol. 28, no. 12, pp. 11131118, 2005.

[43] H. Di Benedetto, M. A. Ashayer Soltani, and P. Chaverot, "Fatigue damage for bituminous mixtures: a pertinent approach," Journal of Association of Asphalt Paving Technologists, vol. 65, pp. 142-158, 1996.

[44] M. Pasetto and N. Baldo, "Unified approach to fatigue study of high performance recycled asphalt concretes," Materials and Structures, vol. 50, article no. 113, 2017. 

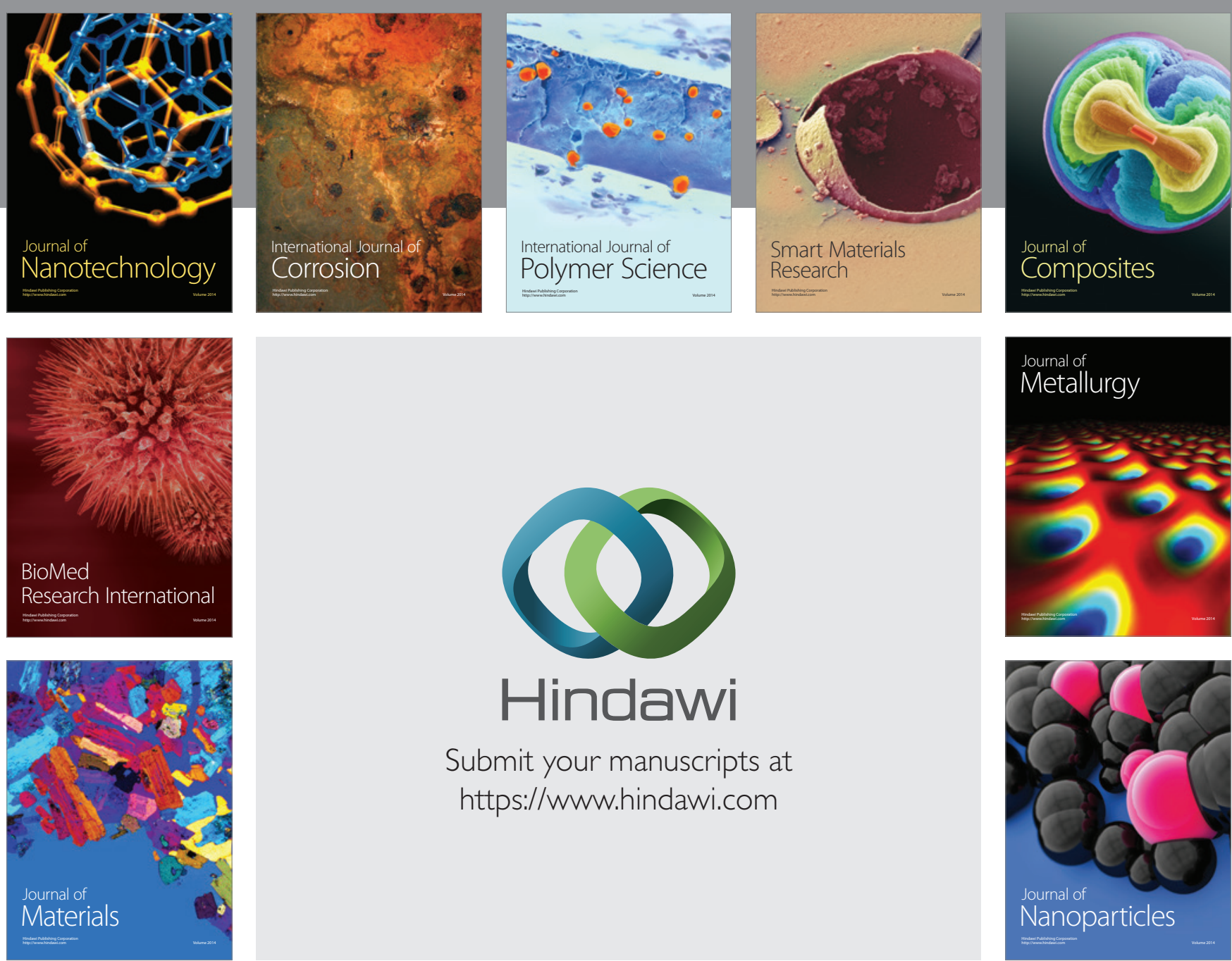

\section{Hindawi}

Submit your manuscripts at

https://www.hindawi.com

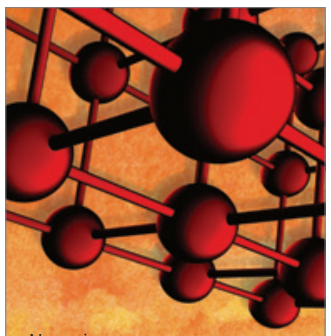

Materials Science and Engineering
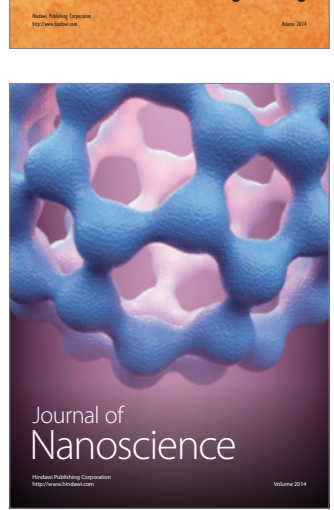
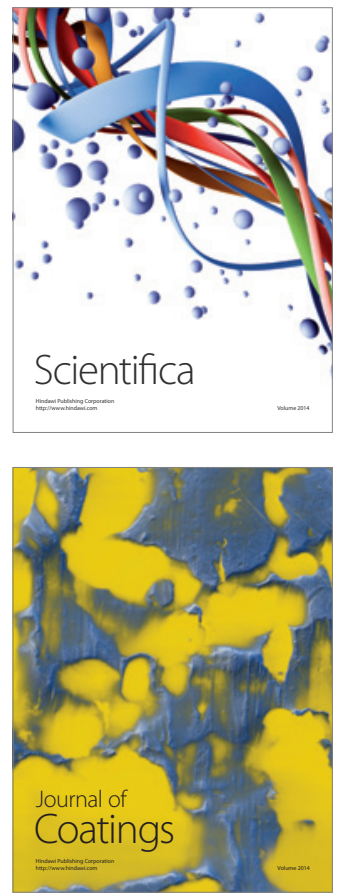
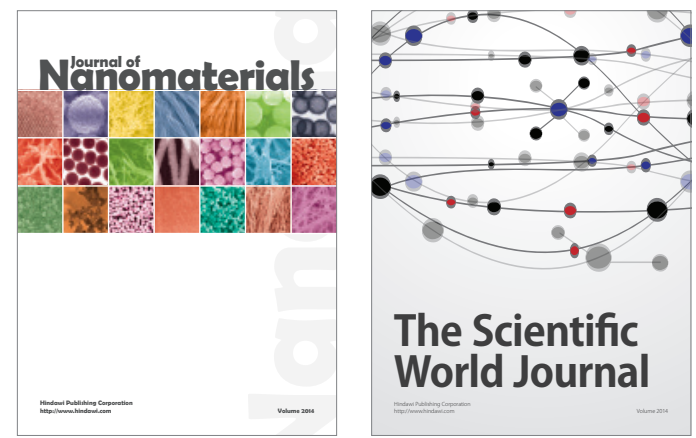

The Scientific World Journal
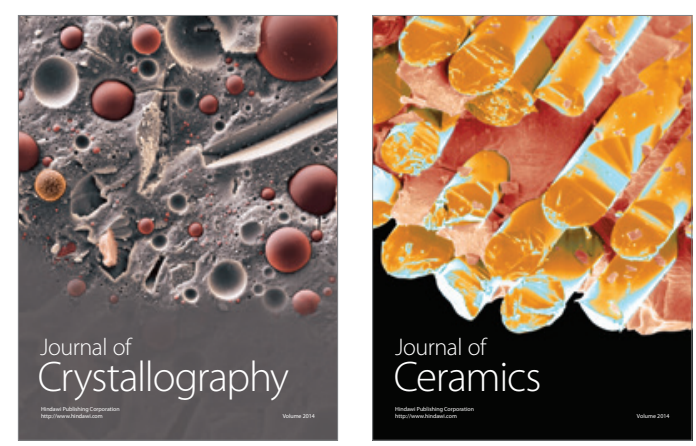
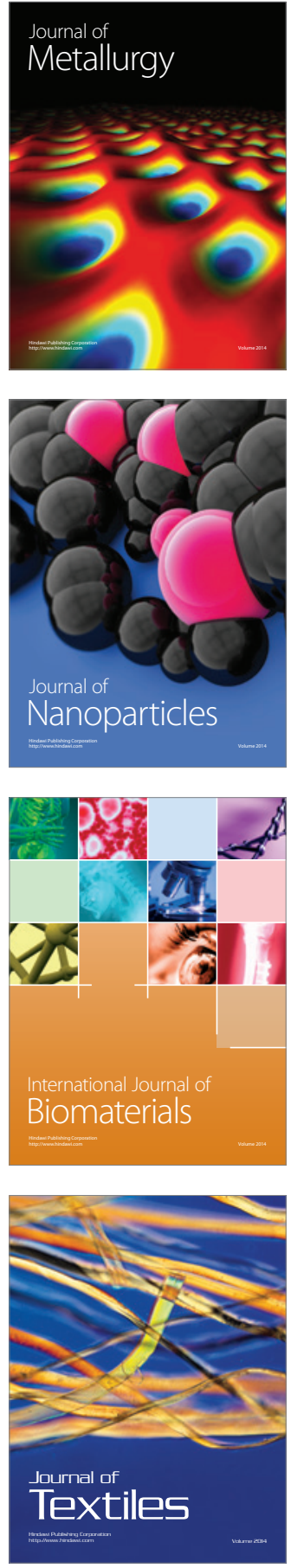